\title{
COMPONENTE CURRICULAR "PLANEJAMENTO E AVALIAÇÃO” E SUAS CONTRIBUIÇÕES PARA A FORMAÇÃO DOCENTE
}

\section{CURRICULAR COMPONENT "PLANNING AND EVALUATION" AND ITS CONTRIBUTIONS FOR TEACHER EDUCATION}

\begin{abstract}
Alachermam Braddylla Estevam da Silva ${ }^{25}$ Maria de Fátima Alves ${ }^{26}$

RESUMO: O presente artigo tem como objetivo identificar as contribuições do componente curricular Planejamento e Avaliação na formação de alunos estagiários do Curso de Letras da Universidade Federal de Campina Grande (UFCG). Esse componente contempla um trabalho articulado com as disciplinas "Paradigmas de ensino" e "Estágio Supervisionado". O arcabouço teórico metodológico baseia-se nos pressupostos da Linguística Aplicada (MOITA LOPES, 2013), no planejamento de ensino no âmbito da Didática das Línguas (DOLZ, 2014), na Sequência Didática de Gêneros (DOLZ e SCHNEUWLY, 2004; BARROS, 2014; COSTAHUBES, 2014) e no Projeto Político Pedagógico do Curso de Letras-UFCG. Podemos considerar que tal disciplina se encontra relacionada com o paradigma da complexidade (FREIRE; LEFFA, 2013), ao considerar que a formação não pode ser vista de forma fragmentada, mas sim, que requer processos de qualificação contínua abordando uma visão crítica, reflexiva e transformadora na formação, que tem como foco o processo e não apenas o produto. Para atingirmos nosso objetivo, analisamos um cronograma de atividades para o trabalho com o gênero Crônica produzido por um aluno estagiário. Como resultados, constatamos a apropriação, por parte do aluno, dos aspectos teórico-metodológicos desenvolvidos no planejamento de atividades didáticas (atividade diagnóstica, plano de ensino, sequência didática, cronograma de atividades) a serem usadas em suas práticas de ensino.
\end{abstract}

PALAVRAS-CHAVE: Planejamento de ensino. Cronograma de atividades. Sequência Didática de Gêneros. Formação Docente.

ABSTRACT: The objective of this article is to identify the contributions of the curricular component "Planning and Evaluation" in the training of internship in the Course of Letters of the Federal University of Campina Grande (UFCG). This component includes a work articulated with the disciplines "Teaching Paradigms" and "Supervised Internship". The theoretical-methodological framework was based on the assumptions of Applied Linguistics (MOITA LOPES, 2013), in the planning of Language Didatic Teaching (DOLZ, 2014), in the Didactic Sequence of Genres (DOLZ \& SCHNEUWLY, 2004; BARROS, 2014; COSTA-HUBES, 2014) and the Political Pedagogical Project of the Course of Letters of the UFCG. We may consider that this research is identified in the field of the complexity paradigm (Freire, Leffa, 2013), considering that it is not a fragmented form of vision, but requires selection processes from a critical, reflexive and reflective perspective, which focuses on the process and not just on the product. To accomplish the objective, we analyze a schedule of activities for the work with the genre Chronic produced by a internship student. As results, we verified the appropriation by the student of the theoretical-methodological aspects developed in the planning of didactic activities (diagnostic activity, teaching plan, didactic sequence, schedule of activities) to be used in their teaching practices.

KEYWORDS: Teaching planning. Schedule of activities. Didactic Sequence of Genres. Teacher training.

\section{Introdução}

Pensar sobre a relação entre teoria e prática no contexto da formação inicial é algo complexo. Pois, esse processo na graduação tem muitos desafios, os quais se relacionam à identidade dos cursos de formação, seus componentes curriculares, seus projetos pedagógicos e o distanciamento teoria-prática dos conhecimentos trabalhados.

\footnotetext{
${ }^{25}$ Mestranda do Programa de Pós-Graduação em Linguagem e Ensino (UFCG). Bolsista CAPES. E-mail: alashermam_T@hotmail.com

${ }^{26}$ Doutora em Linguística e Professora Associada da Unidade Acadêmica de Educação (UAED) e do Programa de Pós-Graduação em Linguagem e Ensino (POSLE) da UFCG, Campina Grande-PB, Brasil. (UFCG). E-mail: fatima.uaed@gmail.com
} 
Os estudos realizados na área de formação docente através de Tardif (2014), Moita Lopes (2013), Pennycook (2007), Pimenta (2006) têm mostrado a necessidade de (re) pensar a formação dos professores de línguas enfatizando a práxis como um espaço de reflexão, tendo como meta a construção de saberes e novas proposições para a ação educativa. Nesse caminho, problematizamos a questão de muitos professores, em suas práticas de ensino, partirem de um trabalho espontaneísta, isto é, da sua intuição sobre atividades propostas e não do seu efetivo conhecimento das teorias que subsidiam a prática, desvalorizando, a nosso ver, o planejamento de atividades didáticas. O que é proveniente, entre outros fatores, de lacunas na formação inicial. Assim, novas perspectivas de formação visam conduzir professores e alunos a uma reflexão sobre suas práticas direcionadas a uma linha crítica, e a partir disso, reconstruir ou desconstruir todo o tipo de conhecimento fixo, pronto ou definido em termos de condições sociais e/ou processos de ensino-aprendizagem perpassados histórico e culturalmente como corretos (OLIVEIRA, 2014).

Conforme Pimenta (2006), os aspectos teórico-práticos, por exemplo, sinalizam a possibilidade de que a partir da formação teórico-epistemológica construída pelo docente, torna-se possível agir de forma diferente daquela idealizada teoricamente. Dessa forma, o referencial teórico não determinará a prática, nem o referencial da prática justificará o teórico, ambos conjuntamente contribuirão para a significação dos conhecimentos teóricos e práticos dos saberes e fazeres docente.

O material para a investigação deste artigo foi gerado em uma pesquisa ${ }^{27}$ mais ampla que se insere no âmbito da Linguística Aplicada (LA), uma vez que buscamos relacionar o trabalho do professor em formação inicial, a linguagem, o ensino e a aprendizagem de Língua Portuguesa. As pesquisas em LA envolvem formulação teórica sobre o uso da linguagem em contextos diversos, no processo de ensino e de aprendizagem da língua (materna ou estrangeira), de tal forma que, embora se centre na resolução de problemas específicos e opere com conhecimentos teóricos de outras disciplinas, podem formular seus próprios modelos teóricos à medida que desperta questionamentos os mais diversos sobre a natureza do ensino de línguas e sobre a forma de condução de seu trabalho no espaço escolar (MOITA LOPES, 1996, p. 22-23).

Adotamos para fins de análise uma abordagem qualitativa com base documental. Segundo Denzin (2006, p.17), a pesquisa qualitativa envolve uma abordagem naturalista, interpretativista para o mundo, o que significa que seus pesquisadores estudam as coisas em seus cenários naturais, tentando entender ou interpretar, os fenômenos em termos dos significados que as pessoas a ele conferem. Para tanto, esta pesquisa foi desenvolvida na disciplina $^{28}$ Planejamento e Avaliação do Curso de Letras da Universidade Federal de Campina Grande (UFCG), com alunos do $4^{\circ}$ período do turno diurno. Com relação aos colaboradores, contamos inicialmente com a participação ativa de dezoito alunos regularmente matriculados, os quais responderam um questionário com foco na compreensão do que significa planejar e avaliar. No entanto, em virtude do grande número de alunos envolvidos, bem como do volume de dados coletados (atividade diagnóstica, plano de ensino, cronograma de atividades, sequência didática) e do pequeno espaço destinado a este artigo, fizemos um recorte e decidimos analisar apenas uma das atividades didáticas produzidas por um dos alunos colaboradores, no caso, o cronograma de atividades e seu processo de produção. A escolha pelo cronograma de atividades se justifica porque ele foi um elemento importante no planejamento didático, o qual apontou e norteou o desenvolvimento da

\footnotetext{
${ }^{27}$ Os dados analisados neste estudo fazem parte do corpus de uma pesquisa que está em andamento e que resultará na dissertação do mestrado, desenvolvida no Programa de Pós-Graduação em Linguagem e Ensino (POSLE-UFCG), intitulada "O planejamento de atividades de leitura no contexto do Estágio Supervisionado: um olhar para as sequências didáticas de gêneros".

${ }_{28}^{28}$ Utilizamos "disciplina" e "componente curricular" como equivalentes.
} 
sequência didática e pelo colaborador se justifica mediante seu desempenho na disciplina Planejamento e Avaliação aferido pela maior nota da turma, sem objeções da docente na correção da SD, demonstrando apropriação dos pressupostos teórico-metodológicos, participação efetiva nas aulas, concessão para entrevista semiestruturada e possibilidade de acompanhamento no Estágio Supervisionado.

Nessa perspectiva, buscamos, neste artigo identificar as contribuições do Componente Curricular Planejamento e Avaliação na formação de alunos estagiários do Curso de Letras da UFCG. Ao longo da disciplina ${ }^{29}$, observamos todo um planejamento de atividades desde um questionário sobre o perfil da turma e suas concepções de planejamento de ensino até a produção da sequência didática, do plano de ensino e do cronograma de atividades.

Este artigo está dividido, além das considerações iniciais e finais, em três seções: na primeira tecemos considerações sobre as concepções de planejamento de ensino no âmbito da Didática das Línguas; em seguida, abordamos algumas reflexões sobre o Componente Curricular Planejamento e Avaliação; posteriormente, apresentamos o corpus e desenvolvemos nossa análise.

\section{Planejamento de ensino no âmbito da Didática das Línguas}

A partir da perspectiva da Didática das Línguas no planejamento de ensino, recentes pesquisas sobre a formação docente estão abordando tanto o campo da teoria quanto o da prática escolar e extraescolar, além da ênfase na reelaboração e construção dos objetos de ensino adaptado às situações didáticas.

Segundo Dolz (2014), a Didática das Línguas se configura como uma disciplina plural e emergente que estuda os fenômenos de ensino e aprendizagem das línguas, esta é intrinsecamente transversal (língua materna, língua segunda, língua estrangeira, etc.). Por ter um objeto de estudo multifacetado, em relação ao ensino e aprendizagem, essa Didática se orienta pelos estudos da Ciência da Educação e da Psicologia, e em relação ao desenvolvimento da linguagem, recebe contribuições da Linguística e da Teoria Literária.

Em um contexto mais específico, como o escolar, as didáticas das matérias escolares constituem tecnologias ou engenharias, na medida em que elas visam, inicialmente, à ação e à decisão sobre o plano dos objetivos, dos programas, dos processos de ensino e de aprendizagem e das técnicas de avaliação. Essas didáticas estão, necessariamente, em forte interação com dois conjuntos de disciplinas de referência: relacionadas aos conteúdos a serem ensinados e aos processos de ensino-aprendizagem. É desta última que a didática busca extrair o essencial dos elementos que permitem conceitualizar os problemas, analisar as condições de intervenção, formular e testar as proposições de solução (Ibidem, p. 38).

Neste espaço, a formação do professor assume uma postura transformadora, mediadora e de interação aluno-conhecimento-professor no âmbito da sala de aula, para o desenvolvimento dos sujeitos (alunos) com e pela linguagem. No sentido de assumir o papel de multiplicador do conhecimento, o professor é responsável pelo processo de apropriação do ensino de língua e deve criar um contexto favorável à aprendizagem.

Diante disso, o planejamento das práticas de ensino dá atenção em particular às capacidades dos alunos, às interações, às tarefas realizadas, ao estudo dos objetos efetivamente ensinados na aula de língua, bem como às ferramentas de ensino (Ibidem, p. 44). Cada aula se configura como uma situação didática específica e singular, em que os objetivos e conteúdos são desenvolvidos a partir de métodos e modos de realização do ensino, de

\footnotetext{
29 Durante um semestre letivo, como pesquisadoras, observamos as aulas da disciplina Planejamento e Avaliação, coletamos os documentos que constituem o corpus desta pesquisa e participamos efetivamente na construção de algumas atividades realizadas em sala de aula.
} 
maneira a proporcionar aos alunos conhecimentos e habilidades expressas por meio de uma metodologia compatível com a temática estudada.

Assim, o planejamento de ensino não pode ser visto como uma atividade estanque, e sim, como um processo enquanto prática social, que envolve uma rotina situada de interação, em que os seres humanos, na condição de agentes específicos, fazem funcionar modos estabelecidos de atender a determinadas finalidades. Para tanto, o professor que deseja realizar uma boa atuação docente sabe que deve participar, elaborar e organizar planos em diferentes níveis de complexidade para atender seus alunos. E o resultado desse planejamento é o plano de ensino, que corresponde à previsão dos objetivos e tarefas do trabalho docente para um ano ou semestre; é dividido por unidades sequenciais, objetivos específicos, conteúdos e desenvolvimento metodológico (LIBÂNEO, 1994, p. 225).

Do plano de ensino resultará, ainda, o plano de aula. Segundo Libâneo (1994, p. 225), o plano de aula é a previsão do desenvolvimento do conteúdo para uma aula ou conjunto de aulas e tem um caráter bastante específico, constituindo a sistematização de todas as atividades que se desenvolvem no período em que o professor e o aluno interagem, numa dinâmica de ensino-aprendizagem.

Criado como um procedimento que expande a própria noção de planejamento e que se difere do plano de aula, encontra-se a Sequência Didática (SCHNEUWLY E DOLZ, 2004, p. 64), que corresponde a um redimensionamento do que se julga ensinável: 1) os conteúdos e conhecimentos dizíveis por meio do gênero; 2) os elementos estruturais peculiares aos textos pertencentes ao gênero; e 3) as configurações específicas de unidades de linguagem, traços, principalmente, da posição enunciativa do enunciador e dos conjuntos particulares de sequências textuais e de tipos discursivos que formam sua estrutura.

Situando-se numa vertente sociointeracionista que compreende "[...] a apropriação dos gêneros como um mecanismo fundamental de socialização, de inserção prática nas atividades comunicativas humanas" (BRONCKART, 1999, p.103), uma SD deve focar as capacidades de linguagem ${ }^{30}$ que resultam das operações linguísticas dos sujeitos no agir linguageiro, mediadas pelos contextos de produção.

Nos moldes do grupo genebrino, a sequência didática é vista como conjunto de atividades escolares, organizadas, de maneira sistemática, em torno de um gênero textual oral ou escrito. Ou seja, esse procedimento envolve estudos partindo de um conjunto de atividades com a finalidade de conhecer melhor o gênero, de acordo com as necessidades sociocomunicativas estabelecidas inicialmente. E se constitui da seguinte forma: 1) apresentação da situação (momento de apresentar um problema comunicativo); 2) primeira produção (etapa de diagnóstico das capacidades já adquiridas pelos alunos em torno do gênero a ser trabalhado); 3) módulos (intervenção propriamente dita; 4) produção final (etapa da revisão e- ou reescrita). Ao transpor para o contexto brasileiro, o modelo genebrino de SD tem passado por alterações e ampliações teórico-metodológicas em função das particularidades do sistema de ensino e das condições socioeducacionais do nosso alunado (ARÁUJO, 2013; COSTA-HUBES E SIMONINI, 2014; BARROS, 2014).

É preciso ressaltar que a partir dessas novas perspectivas de planejamento de ensino, o professor-mediador não só desenvolva o projeto de uma SD entre outras ferramentas didáticas, mas também planeje todas as suas etapas de forma sistematizadas com foco na apropriação de um gênero. Portanto, o trabalho com as SD sugere um trabalho intensivo, concentrado em um período limitado - que será determinado pelas condições pedagógicas de cada contexto de ensino particular, tendo como foco a apropriação de uma prática linguageira (BARROS, 2014).

\footnotetext{
${ }^{30}$ As capacidades de linguagem estão, assim, relacionadas às aptidões requeridas do indivíduo para a sua ação linguageira, o que pressupõe sempre a mediação instrumental de um gênero de texto. (BARROS, 2014.)
} 
No contexto dessa discussão, é importante que antes da realização da SD, o professor consiga desenvolver em seu planejamento de ensino um cronograma de atividades, entendido como uma síntese, uma previsão das atividades que serão realizadas, o qual servirá de base para a produção da SD.

\section{O Componente Curricular Planejamento e Avaliação: algumas reflexões}

A formação inicial de professores, em especial, no Curso Letras da Universidade Federal de Campina Grande está regulamentada através da Portaria nº. 90/84 do MEC. O curso de Letras, da Instituição campo de pesquisa, foi criado em 2002, a partir do desmembramento da Universidade Federal da Paraíba. Seu perfil, a partir do Projeto Pedagógico Curricular, consiste na indissociabilidade entre o ensino, a pesquisa e a extensão materializada em três eixos de formação - usuário, especialista e docente. Com esse perfil, o Curso visa estimular o desenvolvimento, por parte de professores e alunos, da capacidade de reflexão, sistemática e contínua, sobre as práticas educativas com as quais se envolvem e que os habilita a orientar as atuais e futuras experiências de aprendizagem, bem como a enfrentar os problemas de ordem teórica, metodológica, política e ética, característicos de sua área de atuação (PERRENOUD, 2002).cA respeito da sua organização curricular, o Projeto Pedagógico do Curso entende que a formação do graduando em Letras- Língua Portuguesa se orienta por três eixos de formação já mencionados anteriormente, sua delimitação é meramente didática, visto que ao longo da graduação, eles se apresentam interrelacionados. Nosso foco de estudo recai sobre o terceiro eixo - docente, o qual diz respeito à Prática como componente curricular e ao Estágio Supervisionado.

Nesse sentido, as ações de formação de professores se orientam pela visão de um profissional que pesquisa sobre os usos da linguagem (MOITA LOPES, 1996), mas também analisa reflexivamente sua prática de ensino (PCN DO ENSINO FUNDAMENTAL, 1998; NÓVOA, 1999; ALARCÃO, 2001) tendo em vista estabelecer uma reconfiguração contínua da relação entre teoria e prática. Para dar consequência a essa compreensão, foram criadas as disciplinas Fundamentos da Prática Educativa, Políticas da Educação, Paradigmas de Ensino, Planejamento e Avaliação, que juntas somam 285 horas. Essas disciplinas de formação docente buscam, desde o início do Curso, delinear o perfil do professor de português e de literatura brasileira, introduzir o Projeto Pedagógico Curso de Licenciatura em Letras-Língua Portuguesa licenciando no contexto educacional em que se dá a prática de ensino de língua materna, literatura e de língua estrangeira, bem como iniciá-lo na observação e avaliação do planejamento e da prática de ensino, a partir do acompanhamento de situações reais, sejam no âmbito da própria Universidade ou no campo efetivo da sua futura atuação profissional.

Optamos pela escolha da disciplina Planejamento e Avaliação para acompanhar o processo teórico-metodológico do planejamento de ensino na formação inicial, já que na disciplina subsequente, Estágio Supervisionado, as orientações são dirigidas apenas com o aluno e seu respectivo orientador.

O Componente Curricular em análise apresenta os seguintes objetivos:

- Geral

I- Conhecer, compreender, contextualizar, analisar, sintetizar e avaliar (criar/construir) os princípios e procedimentos do planejamento e avaliação do ensino de Língua Portuguesa no Ensino Fundamental II e Ensino Médio.

- Específicos

I- (Re) Conhecer, compreender, contextualizar, analisar, sintetizar os tipos, níveis e etapas do planejamento educacional. 
II- (Re) Conhecer, compreender, contextualizar, analisar, sintetizar os elementos do processo de avaliação da aprendizagem.

III- Elaborar um instrumento para geração de dados para avaliação em uma instituição de ensino.

IV-Aplicar um instrumento de geração de dados para avaliação em uma instituição de ensino.

V- Tabular (racionalizar e refletir) os resultados do instrumento.

VI- A partir dos resultados do instrumento, elaborar um plano de ensino da disciplina de Língua Portuguesa.

VII- A partir do plano de ensino da disciplina, construir uma sequência didática para o ensino de Língua Portuguesa.

Evidencia-se que tais objetivos buscam efetivar um trabalho articulado de aspectos teórico-práticos, através, por exemplo, dos objetivos específicos III a V, em que os estagiários irão elaborar um instrumento de análise para ser aplicado em turmas do Ensino Fundamental II e, posteriormente refletir sobre os resultados obtidos nessa etapa diagnóstica. Nesse sentido, o contato com a sala de aula e a elaboração do planejamento de ensino contextualizado com a elaboração do planejamento de ensino no contexto já são evidenciados em tais objetivos e não apenas no Estágio Supervisionado, momento em que a teoria estudada ao longo da formação seria posta em prática. Assim, as atividades da disciplina foram distribuídas na seguinte carga horária: 60 horas de aulas presenciais e 30 horas de atividades (10 horas para a elaboração e aplicação do instrumento para geração de dados para diagnóstico; 08 horas para tabulação dos resultados e elaboração do plano de ensino; 12 horas para a elaboração de uma sequência didática com 10 atividades).

\section{Planejando atividades de Língua Portuguesa no Componente Curricular Planejamento e Avaliação}

Ao pensar na formação inicial docente, faz-se necessário refletir e verificar se o currículo do Curso de Letras dá conta de formar o professor para atuar, de forma competente, no ensino de língua materna, visto que a formação de professores continua ainda hoje prisioneira de modelos tradicionais, de modelos teóricos muito formais, que dão pouca importância à prática e à sua reflexão. E sabemos que é durante o percurso formativo que o futuro profissional adquire grande parte dos conhecimentos, vivências e experiências que contribuirão para o planejamento e atuação em sala de aula.

Conforme Schön (2000) se faz relevante uma postura reflexivo-crítica na formação de professores de línguas, capaz de repensar criticamente a sua prática pedagógica, alterando-a conforme os objetivos e as necessidades dos aprendizes. Portanto, a análise crítica do professor a respeito de sua maneira de ensinar seria o primeiro passo para a formação de um profissional reflexivo.

Diante desse viés, Cunha (2010) argumenta que o papel do professor se transfigurou de um transmissor de informações, considerando a lógica do conhecimento, sem uma contextualização, para um mediador na construção do conhecimento, considerando os diferentes contextos e suas aplicações. Portanto, ao contrário do que propõe o método tradicional, a teoria construtivista de Vygotsky, por exemplo, sob a perspectiva sócio interacionista, destina ao professor a função de agente mediador que, por meio da linguagem, intervém e auxilia na construção e reelaboração do conhecimento do aluno, contribuindo para seu desenvolvimento. 
Ao partir dessas discussões sobre a formação docente e em função do espaço destinado ao presente artigo, nos deteremos na descrição e análise de um cronograma de atividades elaborado por um aluno estagiário do Curso de Letras da UFCG-CG, que desencadeou a produção da SD, esta contemplou além deste cronograma, um plano de ensino e uma atividade diagnóstica. Entretanto, antes da apresentação do cronograma se faz necessário mencionar o processo de construção e mediação teórico-metodológica que a disciplina Planejamento e Avaliação possibilitou aos estagiários. Eis as seguintes etapas:

Quadro 1 - Etapas do planejamento didático na disciplina Planeamento e Avaliação

\begin{tabular}{|c|l|}
\hline $\mathbf{1}^{\mathbf{0}}$ & $\begin{array}{l}\text { Questionário inicial e avaliação diagnóstica: esses instrumentos foram aplicados } \\
\text { no início do semestre letivo aos estagiários na disciplina Planejamento e Avaliação, } \\
\text { com o objetivo de investigar as habilidades que eles já possuíam e as que } \\
\text { precisariam ser ampliadas para planejar e avaliar o ensino de Língua Portuguesa; }\end{array}$ \\
\hline $\mathbf{2}^{\mathbf{o}}$ & $\begin{array}{l}\text { Primeira versão da atividade diagnóstica a ser aplicada aos alunos do Ensino } \\
\text { Fundamental II: esse instrumento tem como foco conhecer o perfil da turma, em } \\
\text { busca de observar aspectos a serem intervencionados; }\end{array}$ \\
\hline $\mathbf{3}^{\mathbf{0}}$ & $\begin{array}{l}\text { Correção da atividade diagnóstica e intervenção no contexto escolar: nessa } \\
\text { etapa, a docente mediou a correção das atividades diagnósticas, as quais foram } \\
\text { aplicadas nas turmas do ensino fundamental II; }\end{array}$ \\
\hline $\mathbf{4}^{\mathbf{0}}$ & $\begin{array}{l}\text { Elaboração do plano de ensino e do cronograma de atividades: esses } \\
\text { instrumentos foram planejados e elaborados a partir dos resultados obtidos na } \\
\text { atividade diagnóstica; }\end{array}$ \\
\hline $\mathbf{5}^{\mathbf{0}}$ & $\begin{array}{l}\text { Elaboração da Sequência Didática: etapa em que os estagiários desenvolvem os } \\
\text { objetivos e a metodologia propostos no cronograma de atividades; }\end{array}$ \\
\hline $\mathbf{6}^{\mathbf{0}}$ & $\begin{array}{l}\text { Questionário aplicado ao final do semestre aos alunos estagiários: esse } \\
\text { instrumento teve como foco de avaliação apreender as concepções dos estagiários e } \\
\text { sua apreciação sobre aspectos teórico metodológicos trabalhados ao longo do } \\
\text { semestre letivo; }\end{array}$ \\
\hline $\mathbf{7}^{\mathbf{0}}$ & $\begin{array}{l}\text { Relatório de Estágio Supervisionado: desencadeadores da familiarização dos } \\
\text { professores em formação inicial com saberes docentes, a partir das primeiras } \\
\text { experiências da escola básica registradas (SILVA et al, 2016). }\end{array}$ \\
\hline
\end{tabular}

Fonte: as autoras.

No conjunto das atividades acima apresentadas, nos detemos, como já foi mencionado, à análise do cronograma de atividades realizado por um dos estagiários matriculados no Componente Curricular Planejamento e Avaliação.

No referido Componente, em análise neste artigo, a orientação para o planejamento de SD apresenta alterações significativas em relação ao conceito genebrino. Assim, tais alterações $^{31}$, influenciadas principalmente pelo contexto do ensino brasileiro, são perceptíveis no cronograma de atividades sobre o gênero Crônica, com foco na capacidade

\footnotetext{
${ }^{31}$ Essas alterações demonstram um novo olhar para as SD no Brasil, como por exemplo, a atividade diagnóstica constituindo-se uma das fases iniciais e imprescindível desse processo. (REINALDO el al, 2018, no prelo).
} 
leitora dos aprendizes de uma turma de $9^{\circ}$ ano, a partir dos resultados obtidos na atividade diagnóstica.

Quadro 2- Cronograma de atividades elaborado pelo aluno estagiário, colaborador da pesquisa.

\begin{tabular}{|c|c|c|}
\hline ATIVIDADE & METODOLOGIA & OBJETIVOS \\
\hline $1^{\mathrm{a}}$ & $\begin{array}{l}\text { Atividade diagnóstica } \\
\text { com o gênero textual } \\
\text { crônica. } \\
\text { (duraçẫo: } 2 \text { aulas) }\end{array}$ & $\begin{array}{l}\text { Avaliar os conhecimentos dos alunos na } \\
\text { leitura do gênero textual crônica; } \\
\text { - Comparar os resultados obtidos na } 1^{\text {a }} \\
\text { atividade diagnóstica com esta; } \\
\text { - Avaliar os conhecimentos dos alunos sobre } \\
\text { a função dos adjetivos no sentido do texto; } \\
\text { - Observar aspectos a serem } \\
\text { intervencionados. }\end{array}$ \\
\hline $2^{a}$ & $\begin{array}{l}\text { Dinâmica para } \\
\text { apresentação e para } \\
\text { estabelecimento das } \\
\text { regras de convivência. } \\
\text { (duração: } 2 \text { aulas) }\end{array}$ & $\begin{array}{l}\text { - Possibilitar a interação entre a turma; } \\
\text { - Refletir sobre aspectos atitudinais } \\
\text { essenciais para o bom convívio e a } \\
\text { harmonia em sala de aula; } \\
\text { - Estabelecer coletivamente regras de } \\
\text { convivência. }\end{array}$ \\
\hline $3^{a}$ & $\begin{array}{l}\text { Leitura compartilhada } \\
\text { de crônica e } \\
\text { encaminhamento de } \\
\text { atividade de } \\
\text { interpretação } \\
\text { extraclasse. } \\
\text { (duração: } 3 \text { aulas - } \\
\text { leitura + correção da } \\
\text { atividade) }\end{array}$ & $\begin{array}{l}\text { - Compartilhar sentidos e sensações } \\
\text { extraídos a partir da leitura; } \\
\text { - Desenvolver estratégias de leitura; } \\
\text { - Observar alguns aspectos característicos do } \\
\text { gênero; } \\
\text { - Analisar caracterização de personagens } \\
\text { e/ou espaços por meio de adjetivos. }\end{array}$ \\
\hline $4^{a}$ & $\begin{array}{l}\text { Aula expositiva- } \\
\text { dialogada sobre } \\
\text { estrutura e elementos da } \\
\text { narrativa na crônica. } \\
\text { (duração: } 3 \text { aulas) }\end{array}$ & $\begin{array}{l}\text { Aprofundar o conhecimento dos alunos } \\
\text { sobre os elementos da narrativa; } \\
\text { Desenvolver a percepção dos movimentos } \\
\text { da narrativa; } \\
\text { - Identificar os elementos que compõem a } \\
\text { narrativa; } \\
\text { - Observar e analisar a contribuição dos } \\
\text { elementos para a construção da narrativa. }\end{array}$ \\
\hline \multirow[t]{2}{*}{$5^{a}$} & $\begin{array}{l}\text { Leitura compartilhada } \\
\text { de crônica e atividade } \\
\text { em sala. (duração: } 4 \\
\text { aulas - leitura }+ \\
\text { resolução da atividade } \\
+ \text { correção da } \\
\text { atividade) }\end{array}$ & $\begin{array}{l}\text { - Compartilhar sentidos e sensações } \\
\text { extraídos a partir da leitura; } \\
\text { - Desenvolver estratégias de leitura; } \\
\text { - Observar alguns aspectos característicos do } \\
\text { gênero. }\end{array}$ \\
\hline & Aula expositiva- & $\begin{array}{l}\text { - Aprofundar o conhecimento dos alunos } \\
\text { sobre a classe de palavras adjetivo (e a } \\
\text { locução adjetiva); }\end{array}$ \\
\hline
\end{tabular}




\begin{tabular}{|c|c|c|}
\hline $\mathbf{6}^{\mathbf{a}}$ & $\begin{array}{l}\text { dialogada sobre uso } \\
\text { adjetivos e } \\
\text { concordância nominal } \\
\text { no texto. (duração: } 4 \\
\text { aulas) }\end{array}$ & 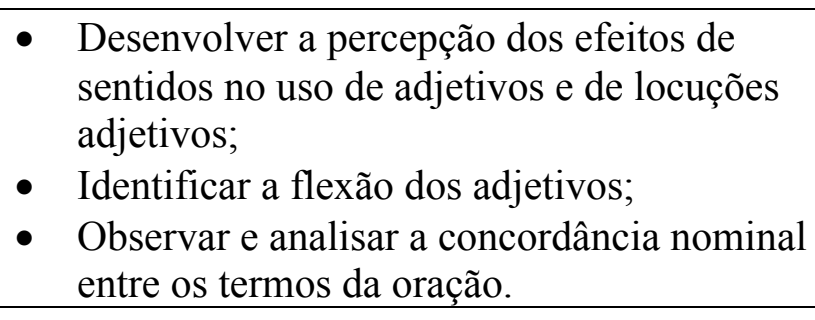 \\
\hline $7^{a}$ & $\begin{array}{l}\text { Leitura compartilhada } \\
\text { de crônica (duração: } 2 \\
\text { aulas) }\end{array}$ & $\begin{array}{l}\text { - Compartilhar sentidos e sensações } \\
\text { extraídos a partir da leitura; } \\
\text { - Desenvolver estratégias de leitura; } \\
\text { - Observar e analisar os elementos da } \\
\text { narrativa; } \\
\text { - } \quad \text { Refletir sobre aspectos atitudinais. } \\
\end{array}$ \\
\hline $8^{\mathrm{a}}$ & $\begin{array}{l}\text { Seminário em grupo } \\
\text { para apresentação da } \\
\text { leitura de crônicas. } \\
\text { (duração: } 5 \text { aulas }-1 \\
\text { grupo por aula) }\end{array}$ & $\begin{array}{l}\text { - Desenvolver o trabalho em grupo; } \\
\text { - Aprofundar, a partir da realização do } \\
\text { seminário, aspectos da oralidade; } \\
\text { - Avaliar a assimilação dos alunos sobre os } \\
\text { elementos da narrativa; } \\
\text { - Avaliar a leitura dos alunos das respectivas } \\
\text { crônicas. }\end{array}$ \\
\hline $9^{a}$ & $\begin{array}{l}\text { Atividade de revisão } \\
\text { sobre adjetivos e } \\
\text { concordância nominal. } \\
(3 \text { aulas }- \text { resolução da } \\
\text { atividade }+ \text { correção da } \\
\text { atividade) }\end{array}$ & $\begin{array}{l}\text { Observar e analisar o uso de adjetivos e } \\
\text { locuções adjetivas; } \\
\text { - Observar e analisar os efeitos de sentido } \\
\text { dos usos de adjetivos e locuções adjetivas; } \\
\text { - Observar e analisar a concordância nominal } \\
\text { entre os termos da oração. }\end{array}$ \\
\hline $10^{\mathrm{a}}$ & $\begin{array}{l}\text { Prova escrita. } \\
\text { (duração: } 2 \text { aulas) }\end{array}$ & $\begin{array}{l}\text { - Avaliar o avanço do aluno a partir dos } \\
\text { conteúdos estudados. }\end{array}$ \\
\hline
\end{tabular}

A partir desse cronograma de atividades, percebemos entre outros aspectos, quatro pontos relevantes. O primeiro trata da reconfiguração da SD pelo estagiário em seu planejamento de ensino, no qual ele inicia com uma atividade diagnóstica, que lhe possibilitou informações sobre os conhecimentos prévios da turma a respeito do gênero e de lacunas sobre os conhecimentos linguísticos a serem trabalhados. Então, se faz notório perceber uma apropriação de conhecimentos teóricos que embasaram a produção da SD por parte do estagiário, a partir, por exemplo, dessa reconfiguração conforme os moldes brasileiros, que segundo Barros (2014) requer planejamento, diagnósticos iniciais, coerência na proposição dos objetivos de cada módulo, articulação entre objetivos traçados e atividades propostas, criatividade e coerência na elaboração de atividades, tarefas e dispositivos didáticos. Dessa forma, compreendemos que ao utilizar essa ferramenta didática houve uma apropriação não somente de sua estrutura de base, mas, sobretudo de sua dinâmica de funcionamento.

O segundo ponto diz respeito aos aspectos teórico-metodológicos trabalhados no Componente Curricular, de forma integrada, visto que os aspectos teóricos não foram trabalhados em detrimento dos aspectos práticos. Por exemplo, ao participar das aulas expositivas na disciplina, os estagiários, sob mediação da docente, elaboraram e discutiram seminários sobre aspectos teórico-metodológicos como: concepções de planejamento e de avaliação, eixos do ensino de língua (oralidade, escrita, leitura e análise linguística), gêneros textuais, que serviram como arcabouço teórico para posteriormente produzirem e aplicarem suas SD. Assim, nesse cronograma evidenciamos a utilização de conceitos sobre estratégias 
de leitura (ROJO, 2009; KOCH E ELIAS, 2006), consideradas fundamentais e de extrema relevância à realização de uma leitura proficiente, isto porque, as estratégias devem ser foco de ensino e aprendizagem em todas as áreas disciplinares, uma vez que são extremamente importantes para facilitar a compreensão e a aprendizagem dos textos; Os conteúdos atitudinais através da dinâmica de apresentação ( $2^{\mathrm{a}}$ atividade); conceituais, ao explorar as características do gênero, os elementos da narrativa, os aspectos linguísticos $\left(3^{\mathrm{a}}, 4^{\mathrm{a}}, 5^{\mathrm{a}}, 6^{\mathrm{a}}, 7^{\mathrm{a}} \mathrm{e}\right.$ $9^{\text {a }}$ atividade); procedimentais, relacionados às dinâmicas, seminários, aulas expositivadialogadas e atividades ( $8^{\mathrm{a}}$ e $10^{\mathrm{a}}$ atividade), posto que estes três conteúdos não podem ser dissociados um do outro no processo de ensino e aprendizagem; A estrutura composicional do gênero (DOLZ E SCHNEUWLY, 2004), o qual possibilita um trabalho com a língua de forma mais eficaz, contribuindo para a formação de leitores críticos e produtores de textos competentes.

O terceiro ponto mostra a relevância do trabalho com a leitura, que não foi usada como pretexto para trabalhar os outros eixos da língua, mas sim, de forma dialógica, interativa, complexa na produção de sentidos, que possa exigir dos alunos estratégias de leitura envolvendo levantamento de hipóteses, inferências, ativação de conhecimentos prévios, comparação de informações. Nesta perspectiva e sob o viés do Interacionismo Sociodiscursivo (BRONCKART, 1999; BARBOSA, 2016), uma aula de leitura ${ }^{32}$ não deve ser simplesmente para decifrar códigos de uma forma mecanicista, mas sim, uma aula que leve os alunos a buscarem soluções para os seus próprios questionamentos, que os leve a produzir conhecimentos e que os faça usar esse conhecimento de forma que ele possa garantir a sua cidadania no mundo. Isso se concretiza através das variadas atividades propostas que foram apresentadas no cronograma, no intuito de levar os alunos do $9^{\circ}$ ano a se apropriarem de forma progressiva e sistemática dos instrumentos comunicativos e linguísticos necessários à compreensão e produção de textos pertencentes ao gênero.

Por fim, observamos um trabalho integrado com os eixos da língua, pois apesar do foco no cronograma de atividades ser a leitura, o estagiário consegue inserir nas suas atividades aspectos da escrita, da análise linguística e da oralidade, demonstrando uma preocupação em articular e desenvolver reflexões linguísticas a partir dos textos, no intuito dos alunos terem mais chances de internalizarem o conhecimento, uma vez que ele é abordado de forma contextualizada, dando mais sentido ao aprendizado (GONÇALVES; SAITO; NASCIMENTO, 2010). Os próprios autores do grupo de Genebra (DOLZ, NOVERRAZ, SCHNEUWLY, 2004) na sua descrição percebem a ausência de um trabalho sistemático com os eixos linguísticos e têm a ciência de que se trata de um modo incompleto, melhor dizendo, de um modelo aberto que pode e deve integrar outras dimensões do trabalho com a língua.

\section{Considerações finais}

Compreendemos que a formação inicial é um momento em que o futuro professor está vivenciando experiências que nortearão a construção da sua identidade profissional. Nossa análise identificou a importância do Componente Curricular Planejamento e Avaliação para os alunos em formação inicial do curso de Letras no que concerne à capacidade de planejar, articular e produzir atividades didáticas, a exemplo do cronograma de atividades, que aparece

\footnotetext{
32 "O processo de leitura para o ISD pode ser entendido como uma reconstrução que transcenda as formas linguísticas empiricamente observáveis" (BRONCKART, 1999, p. 257). Assim, para que a leitura ocorra é necessário observar os mecanismos de textualização e os mecanismos enunciativos.

Os mecanismos enunciativos [...] referem-se à clarificação dos posicionamentos enunciativos e à da explicitação das modalizações que se aplicam a alguns aspectos do conteúdo temático.

[...] os mecanismos de textualização são, por sua vez, articulados à progressão do conteúdo temático, tal como é apreensível no nível da infraestrutura. (BRONCKART, 1999, p 259-260).
} 
como parte integrante do planejamento da SD. Além disso, nesse processo de aprendizagem se faz necessário destacar a participação efetiva da docente que favoreceu a autonomia dos estagiários na produção do material didático, a saber: atividades diagnósticas, planos de ensino, cronogramas de atividades e as sequências didáticas.

É relevante ressaltar como o aluno estagiário se apropriou dos aspectos teóricometodológicos discutidos ao longo da disciplina, como por exemplo, a (re) configuração da $\mathrm{SD}$ nos moldes brasileiros, iniciando-a com uma atividade diagnóstica que atenta para o contexto escolar e para o nível da turma onde o material será desenvolvido. Dessa forma, se faz necessário mencionar como é importante que os alunos em formação inicial docente se apropriem dessa ferramenta didática, não somente de sua estrutura de base, mas, sobretudo, de sua dinâmica de funcionamento em contextos reais de uso da língua.

Consideramos, portanto, que o Componente Curricular em análise, promoveu nos estagiários, principalmente através do planejamento de ensino desenvolvido ao longo do semestre 2018.1, capacidade de compreender o processo educacional como dinâmico, flexível e desafiador para se fazer e se manter eficaz contribuindo significativamente na formação e atuação docente.

\section{Referências}

ALARCÃO, Isabel (org). Escola reflexiva e nova racionalidade. Porto Alegre: Artmed, 2001.

ARAÚJO, D.L. O que é (e como se faz) sequência didática. Entre palavras, Fortaleza - ano 3, v.3, n.1, jan/jul., 2013.

BARROS, E.M.D. As (re) concepções do trabalho docente no processo da transposição didática de gêneros. IN: ; RIOS-REGISTRO, E. S. Experiências com sequências didáticas de gêneros textuais. Campinas: Pontes, 2014.

BARBOSA, L. P. L. Uma visão interacionista sociodiscursiva de leitura: por uma proposta interventiva para a aula de leitura no ensino básico. Dissertação (Mestrado)- Universidade Federal do Ceará, Programa de Pós-Graduação Profissional em Letras - PROFLETRAS, Fortaleza (CE), 2016.

BRONCKART, J.P. Atividades de linguagem, textos e discursos: por um interacionismo sócio-discursivo. São Paulo: EDUC, 1999.

COSTA-HUBES, T.C.; SIMIONI, C. A. Sequência didática: uma proposta metodológica curricular de trabalho com os gêneros discursivos/textuais. IN: BARROS, E.M.D. de; RIOSREGISTRO, E. S (orgs). Experiências com sequências didáticas de gêneros textuais. São Paulo: Pontes Editores, 2014.

CUNHA, M. I. da. (Org.). Trajetórias e lugares de formação da docência universitária: da perspectiva individual ao espaço institucional. Araraquara, SP: Junqueira \& Marin, 2010. DENZIN, Norman K; LINCOLN, Yvonna. (orgs). Planejamento da pesquisa qualitativa: teorias e abordagens. 2 ed. Porto Alegre: ARTMED, 2006.

DOLZ, Joaquim; NOVERRAZ, Michèle, SCHNEUWLY, Bernard. Sequências didáticas para o oral e a escrita: apresentação de um procedimento. IN: SCHNEUWLY, Bernard; DOLZ, Joaquim (org.). Gêneros orais e escritos na escola. Campinas-SP: Mercado de Letras, 2004. FREIRE, M. M; LEFFA, V. J. A auto-heteroconformação tecnológica. IN: Linguística Aplicada na Modernidade Recente: Festchrift para Antonieta Celani. $1^{\mathrm{a}}$ ed. São Paulo, Parábola editorial, 2013.

KOCH, Ingedore Villaça; ELIAS, Vanda Maria. Ler e compreender os sentidos do texto.

São Paulo: Contexto, 2006. LIBÂNEO, José Carlos. Didática. São Paulo: Cortez, 1994. 
MARCONI, Marina de Andrade; LAKATOS, Eva Maria. Metodologia científica. 6. ed. São Paulo: Atlas, 2011.

MOITA LOPES, L. P. (Org.). Linguística aplicada na modernidade recente: festschrift para Antonieta Celani. São Paulo: Parábola, 2013.

Oficina de linguística aplicada: a natureza social e educacional dos processos de

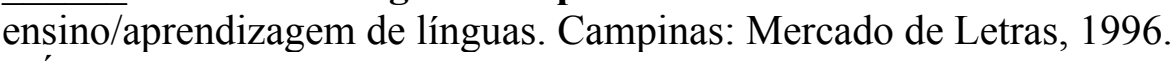

NÓVOA, A. Os professores na virada do milênio: do excesso dos discursos à pobreza das práticas. Revista Educação e Pesquisa, São Paulo, v.25, n.1, jan./jun.,1999.

OLIVEIRA, Maria do Socorro. Projetos de letramento e formação de professores de língua materna / Maria do Socorro Oliveira, Glícia Azevedo Tinoco, Ivoneide Bezerra de Araújo Santos. - Natal: EDUFRN, 2014.

PENNYCOOK, A. Linguística aplicada dos anos 90: em defesa de uma abordagem crítica. In: SIGNORINI, I.; CAVALCANTI, M. C. (Orgs.). IN: Linguística aplicada e transdisciplinaridade: questões e perspectivas. Campinas: Mercado de Letras, 2007. PERRENOUD, Philippe. A prática reflexiva no ofício do professor: profissionalização e razão pedagógica. Porto Alegre: Artmed Editora, 2002.

PIMENTA, S. G. O Estágio na formação de professores: unidade teoria e prática. $7^{\mathrm{a}}$. Ed. Editora Cortez. São Paulo (SP), 2006.

SCHÖN, D. A. Educando o Profissional Reflexivo: um novo design para o ensino e a aprendizagem. Trad. Roberto Cataldo Costa. Porto Alegre: Artmed, 2000.

TARDIF, Maurice. Saberes docentes e formação profissional. Petrópolis, RJ, Vozes, 2014.

Submetido em 29/09/18

Aceito em 15/12/2018 